\title{
Is the laparoscopic choledochal cyst excision and Roux-En-Y hepaticojejunostomy in adults as safe as that in children?
}

Nguyen Thanh Xuan ${ }^{1}$, Nguyen Huu Son ${ }^{2}$ and Ho Huu Thien ${ }^{1 *}$

\begin{abstract}
Background: Laparoscopic cyst excision and Roux-en-Y hepaticojejunostomy for treating congenital choledochal cysts has been proven to be efficacious in children, but its safety and efficacy in adult patients remain uncertain. This study aims to investigate the safety and effectiveness of laparoscopic choledochal cyst excision and Roux-en-Y hepaticojejunostomy in adults compared to those in children patients.

Results: There was no conversion to open surgery in both groups. The mean operative time and hospital duration stay in adults (253.4 min and 11.7 days, respectively) were longer in than those in children (214.7 min and 9.3 days, respectively). Intraoperative blood transfusion was required in one adult and two children. There was not reoperation due to bile leakage in adults compared to those in 2 children. The time from surgery to drainage removal was longer in adults (3.6 vs. 2.9 days). The outcome within three months of discharge was classified as good in $88.2 \%$ of adults and $90.5 \%$ for children. There were no statistically significant differences in early postoperative complications or treatment outcomes between the two groups.

Conclusions: Laparoscopic choledochal cyst excision followed by Roux-en-Y hepaticojejunostomy was safe and efficient in both adults and children. Operative time was longer in adults than in children.
\end{abstract}

Keywords: Laparoscopic excision, Roux-en-Y hepaticojejunostomy, Choledochal cyst

\section{Background}

Choledochal cysts consist of focal or diffuse dilatation of intra- and/or extra-hepatic bile ducts, a congenital abnormality first described by Vater and Ezler in 1723 [1], and later, in 1852 by Douglas. Biliary cysts are usually diagnosed in children. Some studies showed the excellent outcomes of laparoscopic choledochal cyst excision and Roux-en-Y in children $[2,3]$. Nowadays, choledochal cyst excision and Roux-en-Y hepaticojejunostomy have become the technique of choice in children in our

\footnotetext{
* Correspondence: thientrangduc@hotmail.com

${ }^{1}$ Department of Pediatric and Abdominal Emergency Surgery, Hue Central Hospital, 16 Le Loi Street, Hue City, Vietnam

Full list of author information is available at the end of the article
}

hospital [4], but its safety and efficacy in adult patients remain uncertain.

However, approximately 20 to $25 \%$ of cases is found in adults; the incidence of detection is on the rise, mainly because of improved imaging techniques [5]. The majority of patients are female and of far Eastern origin with well-recognized differences in clinical presentation and symptoms between adults and children [6].

In this report, we sought to investigate the safety and effectiveness of laparoscopic choledochal cyst excision and Roux-en-Y hepaticojejunostomy in adults compared to those in children patients.

(c) The Author(s). 2020 Open Access This article is licensed under a Creative Commons Attribution 4.0 International License, which permits use, sharing, adaptation, distribution and reproduction in any medium or format, as long as you give appropriate credit to the original author(s) and the source, provide a link to the Creative Commons licence, and indicate if changes were made. The images or other third party material in this article are included in the article's Creative Commons licence, unless indicated otherwise in a credit line to the material. If material is not included in the article's Creative Commons licence and your intended use is not permitted by statutory regulation or exceeds the permitted use, you will need to obtain permission directly from the copyright holder. To view a copy of this licence, visit http://creativecommons.org/licenses/by/4.0/. 


\section{Methods}

\section{Patients}

Seventy consecutive patients (51 under 16 years of age "children" and 19 older than 16 years of age "adults") diagnosed with type I choledochal cysts underwent laparoscopic choledochal cyst excision and Roux-en-Y hepaticojejunostomy between June 2012 and December 2017.

All procedures were performed by the same surgical team, specialists in both pediatric and adult surgery, according to local practice in Hue Central Hospital, Vietnam [4]. Choledochal cysts were classified according to the Todani classification [7] initially based on preoperative ultrasound, computed tomography scan, and/ or magnetic resonance imaging, and finally confirmed by intraoperative gross examination.

This study was approved by the Ethics Committee Review board of Hue Central Hospital under the reference number: $\mathrm{HCH}-05052012$. Confidentiality was ensured by not writing the names of patients on proforma in accordance the Helsinki Declaration.

\section{Operative technique}

The patient was positioned supine. Full HD Laparoscopy system (4 K laparoscopic system was used from September 2016) is on the patient's right, surgeon and assistant on the patient's left. A 10-mm infraumbilical trocar (supraumbilical in children) was inserted for the camera and $12 \mathrm{mmHg}$ pneumoperitoneum was achieved with carbon dioxide $(8-10 \mathrm{mmHg}$ for children). A $10-\mathrm{mm}$ port was inserted in the left side on the midclavicular line, $3 \mathrm{~cm}$ above the umbilicus. Two additional trocars of $5 \mathrm{~mm}$ in the right hypochondrium. In some cases, a 5 - $\mathrm{mm}$ trocar was placed in the subxiphoid area to elevate the liver. After observing the common bile duct cyst at the liver hilum, the gallbladder was separated from the cyst (Fig. 1). Then, the cyst was separated from the duodenum, the narrowed retroduodenal bile duct was reached and was transected with a $60 \mathrm{~mm}$ endoscopic

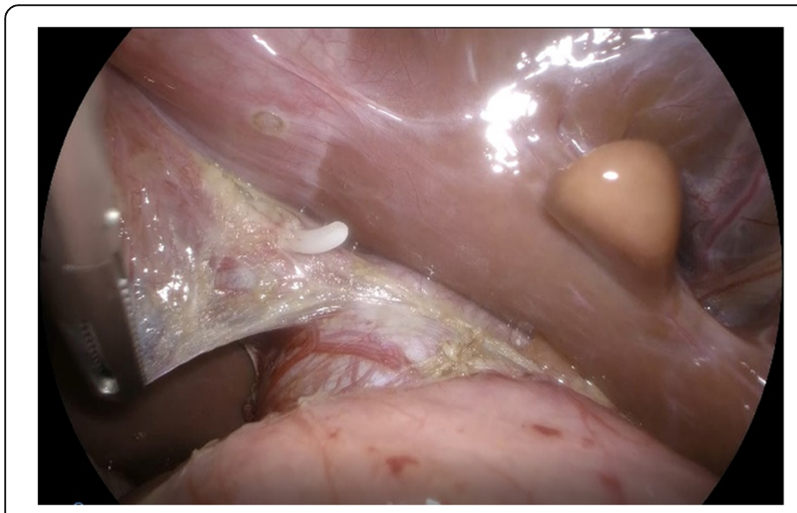

Fig. 1 Transection of the cystic duct stapler if the diameter more than $10 \mathrm{~mm}$; otherwise, it was transected between two hemolocks (Fig. 2). Then, the cyst was separated from the duodenum, the narrowed retroduodenal bile duct was reached and was transected with a $60 \mathrm{~mm}$ endoscopic stapler if the diameter more than $10 \mathrm{~mm}$, otherwise it was transected between two hemolocks (Fig. 2). The latter method was in children in most cases. The free distal end of the cyst was retracted laterally and towards the abdominal wall and was separated from other structures in the liver hilum (right hepatic artery and portal vein). The cyst was dissected up to the highest level that can be technically achieved. The jejunum was transected with an endoscopic stapler $25-30 \mathrm{~cm}$ away from the ligament of Treitz for hepaticojejunostomy. The distal end was advanced in a retrocolic manner, and the Roux loop was brought to the liver hilum. The cyst was transected and extracted out of the umbilical trocar site with the gallbladder at the end of the operation. When the bile duct was opened, it was observed that the biliary bifurcation has been reached (Fig. 3). The hepaticojejunostomy anastomosis was created following an enterotomy with interrupted Vicryl 3/0 sutures (4/0 vicryl in case of children) (Fig. 4). Finally, a side-to-side enteroenterostomy was created by a $60-\mathrm{mm}$ endoscopic stapler between the loop $60 \mathrm{~cm}$ distal from the Roux loop and the afferent loop from the Treitz ligament. In children, the transection of the jejunum and the side to side enteroenterostomy were performed through the enlarge umbilical site about $3 \mathrm{~cm}$. A redon suction drain was placed posterior to the hepaticojejunostomy after completion of cholecystectomy which was remove on third day or less than $3 \mathrm{ml} / \mathrm{h}$.

\section{Follow-up and data analysis}

Eleven patients ( 9 children and 2 adults) were lost to follow-up. Clinical outcome was determined according to the Terblanche classification [8]: grade I, no biliary

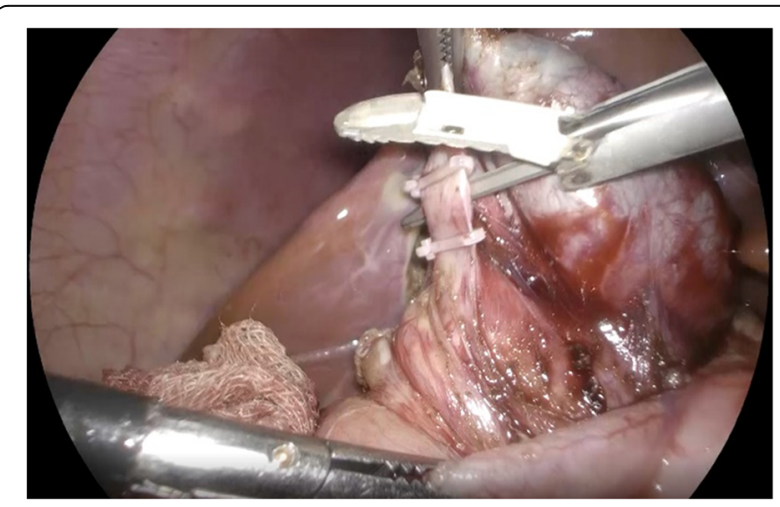

Fig. 2 Distal common bile duct was transected between two hemolocks 


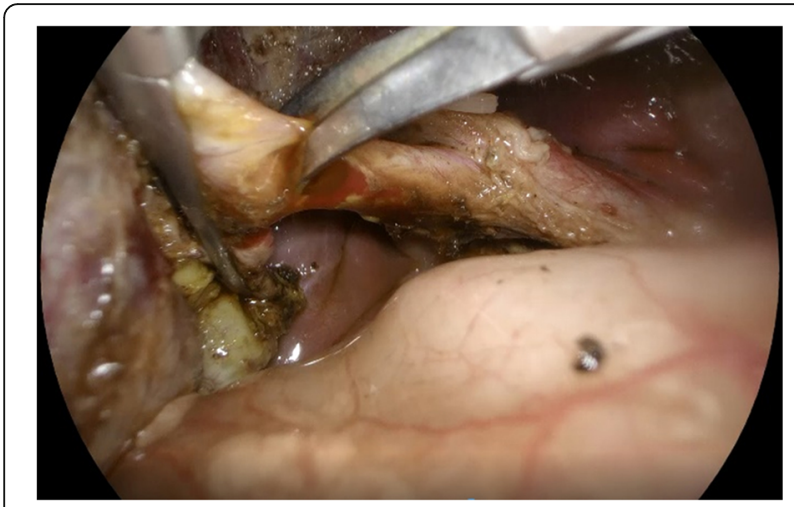

Fig. 3 Common hepatic duct was transected at the hilum

symptoms; grade II, transitory symptoms and no current symptoms; grade III, biliary symptoms requiring medical therapy; and grade IV, recurrent biliary symptoms requiring correction or related to death. Terblanche I, II, and III constituted a clinical success with excellent, good, and fair results, respectively, while Terblanche class IV constituted a poor result.

For comparison between the children and adult groups, we searched the electronic medical records for the following data: patient demographics, operative details, and outcomes such as operation time, need for intraoperative blood transfusion, type of cyst dissection (cyst dissection was considered as standard if the distal part of the cyst was firstly dissected, and non-standard if the cyst was firstly dissected from the proximal part), duration of postoperative hospital stay, and postoperative complications. For descriptive analysis, the frequency or the mean and standard deviation were calculated for each variable. For other continuous variables, independent sample $t$ tests were applied to compare the data between children and adults. Their respective $p$ values and corresponding confidence intervals were provided by SPSS Version 18.0 (SPSS Inc.,

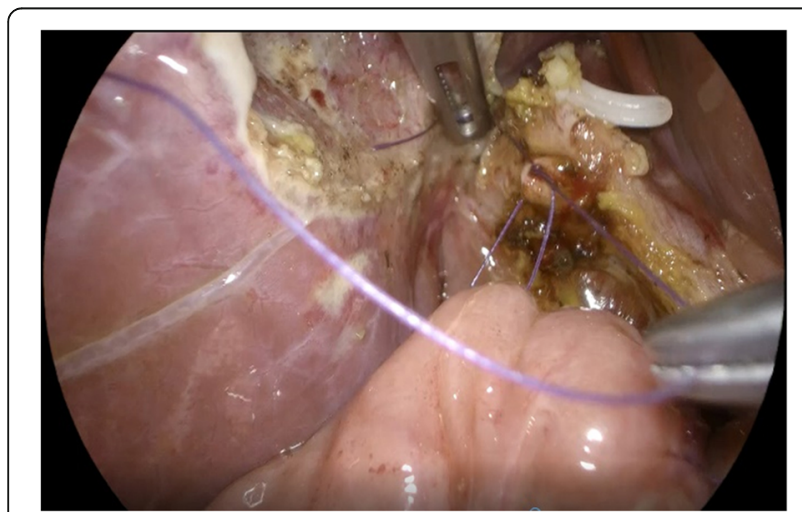

Fig. 4 Hepato-jejuno anastomosis with interrupted suture
Chicago, IL, USA). The statistical significance was set at $p<0.05$.

\section{Results}

Of the 70 patients, 57 were females and 13 were males, 19 were adults, and 51 were children. The mean age at the time of surgery was 12.8 years (range, 2.5 months 75 years), 37.5 years for adults vs. 3.6 years for children. Abdominal pain, fever, and leukocytosis were noted with a significantly higher in adults than those in children, respectively. Conversely, the rate of patients presenting with nausea, vomiting, and jaundice was significantly lower for adults compared to children (Table 1).

For the other laboratory investigation in Table 1, the increasing level of serum bilirubin and hepatic enzyme was significantly lower in adults than in children, respectively.

There was not any conversion to open procedure in both groups.

Table 2 shows the surgical outcomes of laparoscopic choledochal cyst excision and Roux-en-Y hepaticojejunostomy. The mean operative time was $219.8 \pm 64.9 \mathrm{~min}$ (range, 100 360 min. For adults, the mean operative time was $253.4 \pm 55.1 \mathrm{~min}$, range, $120 \sim 360 \mathrm{~min}$, statistically significantly longer than in children $(214.7 \pm 67.9$ min (range, 100 360 min).

Intraoperative blood transfusion was required in one adult and two children. The study showed 7 cases of bile leakage, in which 1 adult and 6 children. Conservative treatment was initially implemented for complications, which resulted in complete resolution in 5 cases. Reoperation was required in two children who had persistent bile leakage (accounted for $3.9 \%$ of all children patients). From April 2016, 12 children and 3 adults were performed the operations with $4 \mathrm{~K}$ laparoscopic system, and we did not recognize any bile leakage postoperatively.

Table 1 Patient characteristics and laboratory findings

\begin{tabular}{llll}
\hline Variables & $\begin{array}{l}\text { Children } \\
(n=51)\end{array}$ & $\begin{array}{l}\text { Adults } \\
(n=19)\end{array}$ & $p$ value \\
\hline Gender & & & \\
$\quad$ Female & $41(80.4 \%)$ & $16(84.2 \%)$ & 0.9842 \\
$\quad$ Male & $10(19.6 \%)$ & $3(15.8 \%)$ & \\
Age (mean) & 3.6 & 37.5 & \\
Symptoms & & & \\
$\quad$ Abdominal pain & $26(51.0 \%)$ & $16(84.2 \%)$ & 0.0246 \\
$\quad$ Jaundice & $17(33.3 \%)$ & $1(5.3 \%)$ & 0.0378 \\
$\quad$ Fever & $18(35.3 \%)$ & $13(68.4 \%)$ & 0.0272 \\
$\quad$ Nausea, vomiting & $25(49.0 \%)$ & $3(15.8 \%)$ & 0.0246 \\
$\quad$ Abdominal mass & $3(5.9 \%)$ & $1(5.3 \%)$ & 0.6299 \\
Laboratory findings & & & \\
$\quad$ Increased serum AST/ALT & $25(49.0 \%)$ & $3(15.8 \%)$ & 0.0246 \\
Increased total bilirubin & $45(88.2 \%)$ & $2(10.5 \%)$ & $<0.0001$ \\
Leukocytosis & $17(33.3 \%)$ & $12(63.2 \%)$ & 0.0471 \\
\hline
\end{tabular}


Table 2 Surgical outcomes of laparoscopic choledochal cyst excision and Roux-en-Y hepaticojejunostomy

\begin{tabular}{|c|c|c|c|}
\hline Variables & $\begin{array}{l}\text { Children group } \\
(n=51)\end{array}$ & $\begin{array}{l}\text { Adult group } \\
(n=19)\end{array}$ & $p$ value \\
\hline Operating time (min) & $214.7 \pm 67.9$ & $253.4 \pm 55.1$ & 0.0295 \\
\hline Number of patient requiring blood transusion & $2(3.9 \%)$ & $1(5.2 \%)$ & 0.6699 \\
\hline Blood transfusion volume & $125.0 \pm 35.4$ & 250 & - \\
\hline Non-standard cyst dissection & $3(5.9 \%)$ & $5(26.3 \%)$ & 0.0177 \\
\hline Time to first flatus (h) & $40.3 \pm 28.5$ & $45.5 \pm 31.3$ & 0.5108 \\
\hline Time to drain removal (days) & $2.9 \pm 1.0$ & $3.6 \pm 1.9$ & 0.0492 \\
\hline Hospital stay (days) & $9.3 \pm 3.4$ & $11.7 \pm 5.5$ & 0.0314 \\
\hline \multicolumn{4}{|l|}{ Complications } \\
\hline $\begin{array}{l}\text { Biliary leakage } \\
\text { Pancreatitis }\end{array}$ & $\begin{array}{l}6(11.8 \%) \\
2(3.9 \%)\end{array}$ & $\begin{array}{l}1(5.3 \%) \\
1(5.3 \%)\end{array}$ & $\begin{array}{l}0.7206 \\
0.6843\end{array}$ \\
\hline Outcome classification according to Terreblanche ${ }^{*}$ & $n=42$ & $n=17$ & \\
\hline $\begin{array}{l}\text { Good } \\
\text { Fair }\end{array}$ & $\begin{array}{l}38(90.5 \%) \\
4(9.5 \%)\end{array}$ & $\begin{array}{l}15(88.2 \%) \\
2(11.8 \%)\end{array}$ & 0.8277 \\
\hline
\end{tabular}

*Eleven patients ( 9 children and 2 adults) were lost to follow-up

Postoperative follow-up results after hospital discharge to 3 months were classified as good in $88.2 \%$ of adults and $90.5 \%$ for children. There was no malignancy found in both adults and children.

The only statistically significant differences were also found in time to drain removal ( $3.6 \pm 1.9$ vs. $2.9 \pm 1.0, p$ $=0.0492)$ and duration of hospital stay (11.7 \pm 5.5 vs. 9.3 $\pm 3.4, p=0.0314)$ in adults and children, respectively.

Conservative treatment was initially implemented for complications, which resulted in complete resolution in seven cases. Reoperation was required in two patients who had persistent bile leakage. Postoperative follow-up results after hospital discharge to 3 months were classified as good in $90.5 \%$ of children and $88.2 \%$ for adults. There was not malignancy found in both children and adult.

\section{Discussion}

Congenital bile duct cysts, although a pediatric disease, can be detected in adults. It is more common in far eastern countries such as China, Korea, Japan, and Vietnam. Although there are various classifications, the most common type (78\%) is fusiform dilatation of the extrahepatic bile ducts (Todani Type I) [9]. Laparoscopic choledochal cyst excision and hepaticojejunostomy in children is widely accepted, and several studies have described the advantages of laparoscopic surgery $[10,11]$. Liem NT et al. reported laparoscopic choledochal cyst excision and reconstruction of the biliary-digestive system as safe and effective with cases of a large number of choledochal cyst patients $[10,12]$.

Our results confirm that choledochal cysts, essentially a congenital disease, can be silent until adulthood. While certain differences have been described in the symptomology, and clinicopathology laparoscopic choledochal cyst excision and hepaticojejunostomy is safe and effective in adults as well as in children.

Several authors have indicated that the signs and symptoms of patients with choledochal cysts as well as the clinicopathological characteristics differ between children and adults $[5,13,14]$. The classical triad of jaundice, right upper quadrant pain, and a palpable mass has been reported to occur more often in children compared to adults in whom cholangitis, liver abscess, biliary cirrhosis, pancreatitis, cholangiocarcinoma, and antecedent biliary tract disease have been observed more commonly [14]. While choledochal cysts may remain asymptomatic for many years and be diagnosed incidentally, when asymptomatic patients undergo imaging studies for a seemingly unrelated reason, many patients have a long history of digestive tract disorders [13]. Thus, the differences in circumstances of discovery are more of a diagnostic nature than disease related. This may also explain why adult patients are seen initially with complicated clinical presentations more often than children in our study (Table 1) as well as other authors $[5,13,14]$.

One of the main complications of laparoscopic choledochal cyst excision is bleeding that can potentially require intraoperative or post-operative blood transfusion. We met the severe inflammation of the cyst more often in adults than children, but careful dissection with surgical energy device the bleeding could be avoided. Both Liem et al [10]. and Tang et al [15]. mentioned the need for intraoperative blood transfusion. In our study, one adult and two children required blood transfusion, and the difference was not significantly seen. 
Concerning postoperative complications, several authors have reported post-operative complications after cyst excision and anastomosis, including postoperative bile leakage $[11,16,17]$ and pancreatitis (said to be more frequent in patients with preoperative pancreatitis) [18]. Compared to other studies, the rates of early complications of our study were low. We noted three cases of pancreatitis and seven cases of bile leakage ( 1 adult and 6 children), which resulted in complete resolution in 5 cases. The rate of bile leakage was not significantly different in adults compared to children (Table 2). However, reoperation was required in two children with persistent bile leakage. Besides, the rate of pancreatitis was not significantly different between the two groups.

No postoperative complications have been observed within 3 months in our study, but our follow-up was far from ideal. This is one of the limitations of our study. Postoperative follow-up after hospital discharge to 3 months, the outcome was classified as good in $88.2 \%$ of adults and $90.5 \%$ of children. There were no significant differences between the two groups $(p=0.8277)$.

During the study, several tips have been suggested to reduce the rate of bile leakage. Firstly, electrical dissection should not be overused, and scissors should be used to cut the hepatic duct. Secondly, the anastomosis should be carefully checked before the end of the operation. Thirdly, a bowel loop with a good arterial arcade with sufficient length should be chosen to construct a tension-free anastomosis. Finally, the using of $4 \mathrm{~K}$ laparoscopic system with good images help us a lot in cyst dissection as well as hepaticojejunostomy, which was shown in our later study.

\section{Conclusions}

In our series of 70 patients, $27 \%(n=19)$ were adults. Laparoscopic choledochal cyst excision and Roux-en-Y hepaticojejunostomy in adults was as safe and effective as that in children. Operative time and hospital duration stay were longer in adults than in children. The rate of bile leakage was not significantly higher in adults compared to that in children.

\section{Acknowledgements}

The authors thank A. Fingerhut for his assistance.

\section{Authors' contributions}

HHT and NTX has contributed to format the design of the study and revised the collected data. NTX and NHS has done the main work of the statistical data analysis. HHT and HTX has shared the operational work of the study and writing works. HHT and NTX has recruited the participants, contributed to the operational works, interpretation, and analysis of the results. Finally, all authors have read and approved the manuscript.

\section{Funding}

No funding resources.
Availability of data and materials

The corresponding author has full access to all of the data and takes full responsibility for the veracity of the data.

Ethics approval and consent to participate

This study was approved by the Ethics Committee Review Board of Hue Central Hospital under the reference number: HCH-05052012. Confidentiality was ensured by not writing the names of patients on proforma in accordance with the Helsinki Declaration. Written informed consent was obtained from all patients before the study. The steps of operative interferences were explained to all patients. The local ethics committee approved all operative procedures.

\section{Consent for publication}

Not applicable. The manuscript does not contain any individual person's data.

\section{Competing interests}

The authors declare that they have no competing interests.

\section{Author details}

${ }^{1}$ Department of Pediatric and Abdominal Emergency Surgery, Hue Central Hospital, 16 Le Loi Street, Hue City, Vietnam. ${ }^{2}$ Pediatric Center, Hue Central Hospital, Hue City, Vietnam.

Received: 18 March 2020 Accepted: 29 April 2020

Published online: 01 July 2020

\section{References}

1. Soares KC, Arnaoutakis DJ, Kamel I, Rastegar N, Anders R, Maithel S, Pawlik TM (2014) Choledochal cysts: presentation, clinical differentiation, and management. J Am Coll Surg. 219:1167-1180

2. Liem NT (2013) Laparoscopic surgery for choledochal cysts. J Hepatobiliary Pancreat Sci. 20:487-491

3. Song G, Jiang X, Wang J, Li A (2017) Comparative clinical study of laparoscopic and open surgery in children with choledochal cysts. Saudi Med J. 38:476-481

4. Xuan NT, Hiep PN, Thien HH, Vu PA, Thanh PH, Khanh LD, Chau DLM (2013) Laparoscopic excision of choledochal cyst in Hue Central Hospital. Vietnam Laparoscopic surgery and Endoscopy Journal. 1:22-25

5. Woon CY, Tan YM, Oei CL, Chung AY, Chow PK, Ooi LL (2006) Adult choledochal cysts: an audit of surgical management. ANZ J Surg. 76:981986

6. Huang CS, Huang CC, Chen DF (2010) Choledochal cysts: differences between pediatric and adult patients. J Gastrointest Surg. 14:1105-1110

7. Dumitrascu T, Lupescu I, lonescu M (2012) The Todani classification for bile duct cysts: an overview. Acta Chir Belg. 112:340-345

8. Terblanche J, Worthley CS, Spence RA, Krige JE (1990) High or low hepaticojejunostomy for bile duct strictures? Surgery. 108:828-834

9. Soreide K, Korner H, Havnen J, Soreide JA (2004) Bile duct cysts in adults. Br J Surg. 91:1538-1548

10. Liem NT, Pham HD, Dung le A, Son TN, Vu HM (2012). Early and intermediate outcomes of laparoscopic surgery for choledochal cysts with 400 patients. J Laparoendosc Adv Surg Tech A. 22: 599-603.

11. Qiao G, Li L, Li S, Tang S, Wang B, Xi H, Gao Z, Sun Q (2015) Laparoscopic cyst excision and Roux-Y hepaticojejunostomy for children with choledochal cysts in China: a multicenter study. Surg Endosc. 29:140-144

12. Nguyen Thanh L, Hien PD, Dung le A, Son TN (2010). Laparoscopic repair for choledochal cyst: lessons learned from 190 cases. J Pediatr Surg. 45: 540544.

13. Lenriot JP, Gigot JF, Segol P, Fagniez PL, Fingerhut A, Adloff M (1998) Bile duct cysts in adults: a multi-institutional retrospective study. French Associations for Surgical Research. Ann Surg. 228:159-166

14. Mabrut JY, Bozio G, Hubert C, Gigot JF (2010) Management of congenital bile duct cysts. Dig Surg. 27:12-18

15. Tang ST, Yang Y, Wang Y, Mao YZ, Li SW, Tong QS, Cao GQ, Zhao ZX (2011) Laparoscopic choledochal cyst excision, hepaticojejunostomy, and extracorporeal Roux-en-Y anastomosis: a technical skill and intermediateterm report in 62 cases. Surg Endosc. 25:416-422 
16. Ono S, Fumino S, Shimadera S, Iwai N (2010) Long-term outcomes after hepaticojejunostomy for choledochal cyst: a 10- to 27-year follow-up. J Pediatr Surg. 45:376-378

17. Sheng Q, Lv Z, Xu W, Xiao X, Liu J, Wu Y (2017) Reoperation After Cyst Excision with Hepaticojejunostomy for Choledochal Cysts: Our Experience in 18 Cases. Med Sci Monit. 23:1371-1377

18. Acker SN, Bruny JL, Narkewicz MR, Roach JP, Rogers A, Karrer FM (2013) Preoperative imaging does not predict intrahepatic involvement in choledochal cysts. J Pediatr Surg. 48:2378-2382

\section{Publisher's Note}

Springer Nature remains neutral with regard to jurisdictional claims in published maps and institutional affiliations.

Submit your manuscript to a SpringerOpen ${ }^{\circ}$ journal and benefit from:

- Convenient online submission

- Rigorous peer review

- Open access: articles freely available online

- High visibility within the field

- Retaining the copyright to your article

Submit your next manuscript at $\boldsymbol{\sim}$ springeropen.com 